\title{
Research computer network remote education teaching model
}

\author{
Song Baogui \\ Yishui Campus \\ LinYi University \\ Yishui, 276400,China \\ yssfsbg@163.com
}

\begin{abstract}
This paper reviews the network distance education teaching mode, Using the computer education as an example, the analysis of the computer aided teaching method the results in the application of quantitative and qualitative analysis method. Make a certain university 2005 freshmen do level test, according to the principle of no significant difference will be divided into a whole new $\mathrm{N}$. Randomly selected two whole (62) for the test group to participate in university computer teaching reform. At the same time, select the other two whole (62) as the reference object for regular teaching. Period, and the two groups of students in four tests, and the four scores on the quantitative analysis; The network distance education in computer aided teaching experience of teachers and students class separately carried on the interview, At the same time, to student's online autonomous learning time and content monitoring and statistics, and student test scores were compared.
\end{abstract}

Keywords-collaborative teaching; Teaching quality evaluation; Fuzzy hierarchy;

\section{INTRODUCTION}

College Network Teaching has achieved remarkable success in the past years while the coming of information age and the increasing demand to the students' computer competence push college computer teaching towards into the tide of reform. From 2000, college Network teaching has been experiencing reform. Among the freshmen of grade 2005 in some University, six classes were selected to participate in the college Network teaching reform. Four classes are involved in this study. The classes fell into experimental group and control group. The study was conducted during two academic years from Oct 10th 2010 to July 10th 2011. The students of control group were required to attend intensive course 4 periods a week in traditional classroom involving teacher, blackboard and chalks and to attend listening class once two weeks in language lab. They are taught in interactive teaching approach in a studentcentered environment if needed[3-5].

\section{DESCRIPTION}

The course arrangement for the students of experimental group consists two parts: Network learning and Classroom study. They had Network courses 4 periods one week in multimedia classroom in which audio, vision and text are available and have computer course once two weeks in Network lab. Above factors seemed much more similar to the control group. For experimental group, computer assisted Network learning Classroom -study is added. They are required to do Classroom -study two periods a week in computer assisted self-access labs, usually with scheduled task. Besides they can go to the lab at anytime during the week from 5:00 pm to 10:00 pm. The university also provides FTP service in local network to them which contains various resources related to the college computer course and college computer test. They are also entitled to visit the website which is related to the textbook. Students can select any resources according their individual needs and interest. Both groups are required to finish 8 units of each serial of book in the first three terms and 4 units in the forth term. They also have to attended one final exam each term and a College computer Test as the final exam of the forth term.

Both the two groups in the academic year all used the same course syllabus, textbooks, classroom activities, assignments, quizzes and final exams with the same teacher the writer herself. In order to make sure that the original computer proficiency would not become an interfering factor to the study, we chose the subjects by following the steps: First, all the freshmen of grade 2010 were given a proficiency test. The scores were collected as data..Secondly, all the data were keyed into computer and tested by T-test. Thirdly, the students were divided into several groups according to the rule of No significant Difference in results 。 Finally, 4 groups were selected randomly two as experimental group and two as control group. In this study, the 4 classes belong to four different colleges of University. Each group has 62 students. They all had about at least six years of experience of learning computer and most of them had no experience of communicating in computer through the network. The result of T-Test $(\mathrm{T}=-0.0008)$ showed that there was no significant difference in the initial computer proficiency between the experimental group and the control group.

\section{INSTRUMENTS AND METHOD}

In order to accurately reflect the effects of Computer assisted Teaching model in College Network Teaching, the author adopted both the quantitative and qualitative methods. Four tests, interviews and computer monitoring were appointed to be the instrument of this study. 


\section{A. Network computer tests}

Computer tests are appointed to be the instrument in the quantitative research. In the nearly two academic years, one proficiency test was given and three achievement tests were carried out to the two groups at the end of each term as final exams. Another test is College computer test for noncomputer majors as the final exam of the forth term. The tests designed for final exam contains the same items as College computer testfor non- computer majors. But the level of the tests was designed according to the learners' computer level and the teaching goals of each term. The test was designed scientifically and carefully by several experienced teachers. After each test, the evaluation about the validity, reliability, difficulty, discrimination and practicality would be examined by a special software designed by some University to make sure it is suitable and useful.

\section{B. Interviews}

Interview is appointed to be one of the instruments in the qualitative research. In the study, 2 interviews were conducted. One interview was conducted among three teachers who have the Computer-assisted language teaching experience based on the results of the test analysis. After each tests, an interview would be conducted based on the results of the test analysis. The other interview was conducted among the students of the experimental classes. Sixteen students were selected randomly a week after the experiment to find out the students' attitude towards the use of CALL. How they apply it into autonomous learning or some issues which can not be seen from the test results.

\section{Computer recording and monitoring}

During the whole online participation process, the computer recorded the students' learning time, the teacher could easily know the situation of students' participation. Compared with human observation, computer recording is more accurate and objective for the software record everything faithfully. In human observation, the researcher's bias and accidental omission may reduce the validity of data. Therefore, the combination of both should give relatively comprehensive data for analysis.

\section{Data procedures}

The study was composed of the following steps:

1. The first test (proficiency test) was conducted before the process of the computer-assisted teaching model (1)to get deep understanding about the English level of the students and (2) to make the choice of subjects more scientific and accurate.

2. The second test (achievement test) was carries out at the end of the first term. The purpose of its analysis is to make a comparison between the two groups and in each group in order to adjust the teaching approach and other factors to make bigger progress.

3. The third test performed at the end of the second term. Since the experiment has been on for one year, it is time for us to examine whether there are some differences in English competence between the two groups. If the answer is yes, what are they? Meanwhile, solve the probable existing problems for further study.

4. The fourth test can be done at the end of the third term. Students will attend the College English Test (Band 4) for non-English majors next term. The test result can show the students' current English competence level. The teachers can adjust their teaching contents, method and some other factors to help the student in preparing for the CET-4.

5. The fifth test is the College Computer Test, which is an authoritative test in China and has high validity and reliability. This result is meaningful. It can not show the English competence differences between the two groups but also the advantages and disadvantages of the two teaching methods in this kind of authoritative tests.

6. During the process of computer-based online course, the research regularly checked the computer recording and monitored the process of the learning.

7. In this study several informal interviews were conducted at the end of each test. Teachers gave their opinions based on the result analysis. A formal interview was conducted one week after the final test was finished and all the data analysis was made out. The purpose is to draw a conclusion of this study carried for two years and to find out as much as possible information that couldn't be revealed in these tests and possible, to dig out the cause for some unexplainable issue. In addition, suggested improvements were also gathered.

\section{E. Methods of statistical analysis}

The scores of the five tests were keyed into the computer and analyzed by the SPSS (the Statistical Package for Social Science)15.0 statistical programs. Descriptive statistics in this study such as the numbers of subjects, minimum, maximum scores, means and standard deviations are used to give a vivid show of the result.

\section{CHAPTER 4 RESUltS AND DisCUSSION}

\section{A. Data from the first test}

From the table 1, in the first test, the mean score of the two groups are nearly equal. As $\mathrm{T}=-0.008<1.53$, it indicated that the two groups show nearly no difference in this test which made the choice of subjects more scientific and accurate.

\section{B. Data from the second test}

From Figure 1 and Table 2, in the second test, the mean score of the experimental group is higher than that of the control group by about 4 points. As $\mathrm{F}=0.021$ $\mathrm{p}=0.885>0.05$ (Table 4-5) $\mathrm{T}=1.587>1.53$, it indicated that the two groups began to have a little difference in this test but the difference is not significant.

\section{Data from the fifth test}

The Figure 2 shows the differences between the two groups. It can indicate that the scores of experimental group are much higher than that of control group and the scores of the other two items have no significant difference. The total 
scores of experimental group are also much higher than that of control group.

\section{The analysis among the five tests}

From the above tables and diagrams the two groups begins at the same level with $\mathrm{T}=0.0008<1.53$ and shows no significance in the second test. While in the third and forth tests, the significant differences showed apparently. It can be easily seen that the scores of the two groups are all increased from the first term to the forth term but the speed of increasing is not the same. The speed of experimental group performed faster than that of the control group. And from the results, it shows that the scores of the experimental group are much higher than that of the control group by nearly 10 points. The scores of the Computer of the experimental group is higher than that of the control group by only 3 points and the scores of the last item is higher than that of the control by only 5 points. This indicates CALL teaching approach may contribute to the improvement of Computer competence of students whereas there is no significant difference in writing and cloze which are considered to be output skill.

\section{REFERENCES}

[1] William F. Pinar . International Handbook of Curriculum Research[M]. Lawrence Erlbaum.,in 2003.

[2] William F. Pinar. What is Curriculum Theory[M]. Lawrence Erlbaum,in 2004.

[3] Charles Fisher,David C. Dwyer, Keith Yocam . Education \& Technology:Reflections on Computing in Classrooms[M]. Apple Press, Jossey-Bass Publishers, San Francisco, in 1996.

[4] Alderson, J.C. \& A.H. Urquhart. 1984. Introduction: What is Reading. Cambridge: Cambridge University Press.

[5] Allen, E. \& M. Demel. 1988. Comprehension and text Genre: An analysis of secondary school foreign language readers. Modern Language Journal, (72), 163-172.

TABLE I. THE FIRST TEST (SEP 2010)

\begin{tabular}{|l|l|l|l|l|l|l|}
\hline & Mean & Median & Std. Deviation & Minimum & Maximum & T-test \\
\hline EG & 35.113 & 35.000 & 7.3965 & 21.0 & 50.0 & -0.008 \\
\hline CG & 35.123 & 35.010 & 7.3965 & 21.0 & 50.0 & \\
\hline
\end{tabular}

TABLE II. THE SECOND TEST (JAN. 2006)

\begin{tabular}{|l|l|l|l|l|l|l|}
\hline & Mean & Median & Std. Deviation & Minimum & Maximum & T-test \\
\hline EG & 58.048 & 58.000 & 8.7435 & 37.0 & 81.0 & 1.587 \\
\hline CG & 54.419 & 53.500 & 9.1069 & 22.0 & 70.5 & \\
\hline
\end{tabular}

TABLE III. THE COMPARISON OF THE FIVE TESTS

\begin{tabular}{|c|c|c|c|c|c|c|c|}
\hline Item & Group & Number & Mean & Std. Variation & F Value & $\mathrm{P}$ & T Value \\
\hline \multirow{3}{*}{$\begin{array}{l}\text { Computer- 2- } \\
\text { Score }\end{array}$} & EG & 62 & 429.81 & 55.261 & \multirow{3}{*}{.758} & \multirow{3}{*}{.387} & \multirow{3}{*}{ 2. 259} \\
\hline & $\mathrm{CG}$ & 62 & 401.10 & 44.182 & & & \\
\hline & $\mathrm{CG}$ & 62 & 57.81 & 18.945 & & & \\
\hline \multirow[t]{2}{*}{$1^{\text {st }}$ test } & EG & 62 & 35.334 & 7.04060 & \multirow{2}{*}{.000} & \multirow{2}{*}{ 1. 000} & \multirow{2}{*}{-0.008} \\
\hline & $\mathrm{CG}$ & 62 & 35.350 & 7.04060 & & & \\
\hline \multirow[t]{2}{*}{$2^{\text {nd }}$ Test } & EG & 62 & 58.05 & 8.8160 & \multirow{2}{*}{.021} & \multirow{2}{*}{.885} & \multirow{2}{*}{1.587} \\
\hline & $\mathrm{CG}$ & 62 & 54.42 & 9.107 & & & \\
\hline \multirow[t]{2}{*}{$3^{\text {rd }}$ test } & EG & 62 & 69.839 & 8.1745 & \multirow{2}{*}{.258} & \multirow{2}{*}{.613} & \multirow{2}{*}{1.978} \\
\hline & $\mathrm{CG}$ & 62 & 65.76 & 8.033 & & & \\
\hline \multirow[t]{2}{*}{$4^{\text {th }}$ test } & EG & 62 & 78.82 & 7.2554 & \multirow{2}{*}{ 1. 319} & \multirow{2}{*}{.255} & \multirow{2}{*}{2.225} \\
\hline & $\mathrm{CG}$ & 62 & 73.37 & 9.099 & & & \\
\hline
\end{tabular}




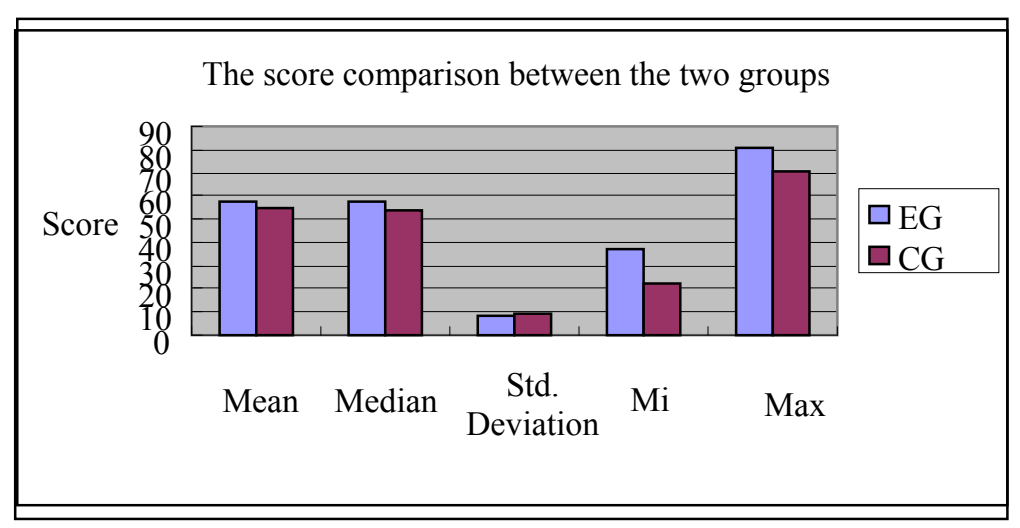

Figure 1. The score comparison of two Groups in the 2nd test

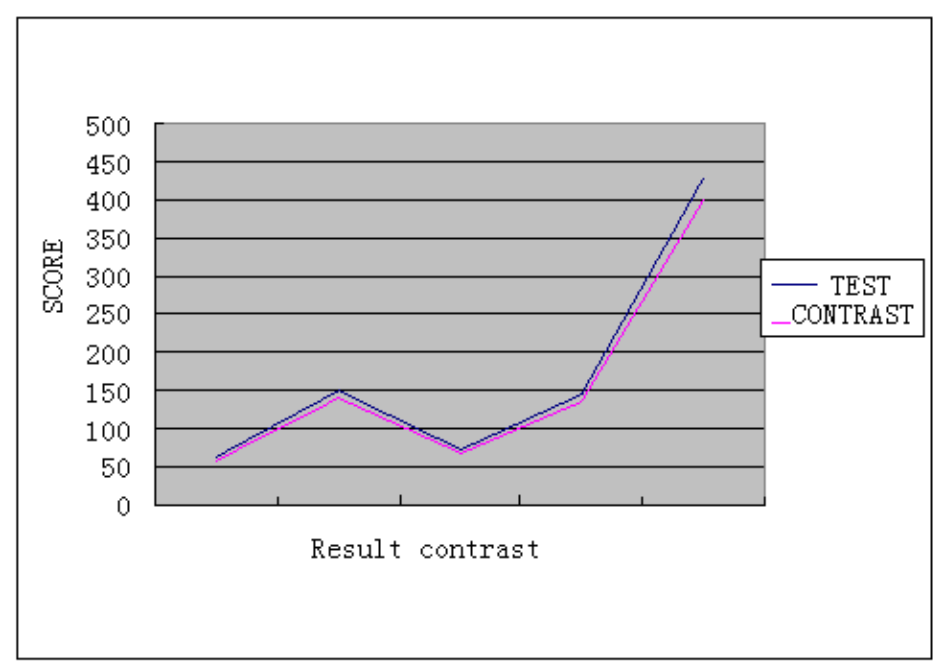

Figure 2. The comparison on the performance in Computer -2 